\title{
Efeito do banho de imersão de diflubenzuron no sêmen do jundiá Rhamdia quelen parasitado por Lernaea cyprinacea
}

\section{The effects of diflubenzuron immersion bath on sperm of jundiá Rhamdia quelen with Lernaea cyprinacea}

\author{
Rodrigo Gasparoto Mabilia'; Silvia Maria Guimarães de Souza ${ }^{2 *}$; \\ Eneder Rosana Oberst ${ }^{3}$
}

\begin{abstract}
Resumo
Os efeitos de produtos terapêuticos e outros poluentes, sobre a produção espermática de peixes têm sido objeto de pesquisas. O diflubenzuron(DFB) é muito utilizado no tratamento de ectoparasitos de peixes, sendo que nos Estados Unidos e Europa seu uso é controlado em função do grande potencial de impacto ambiental. No Sul do país, muitos produtores utilizam o DFB em banhos de 24 horas numa única aplicação. O presente trabalho submeteu 64 jundiás (Rhamdia quelen) infestados por Lernaea cyprinacea a quatro tratamentos, grupo controle e três doses de DFB, $(0,0 \mathrm{mg} / \mathrm{L} ; 0,01 \mathrm{mg} / \mathrm{L} ; 0,1 \mathrm{mg} / \mathrm{L}$ e $1 \mathrm{mg} / \mathrm{L}$ ) sob a forma de banhos de imersão num período de 24 horas. Ao final do período experimental, foram realizadas a coleta e a avaliação do sêmen dos peixes. Não houve diferença entre os parâmetros avaliados: volume, aspecto (aparência e cor), duração da motilidade e concentração espermática. $\mathrm{O}$ produto mostrou-se ineficaz em banhos de 24 horas para parasitos adultos e copepoditos.

Palavras-chave: Sêmen, motilidade espermática, concentração espermática, diflubenzuron, banho, Rhamdia, Lernaea cyprinacea
\end{abstract}

\begin{abstract}
The effects of therapeutics products and other poluents over fish sperm have been research issues. The diflubenzuron (DFB) is widely used against fish ectoparasites. For USA and Europe, its use is restricted, due the large potential of environment impact; but in south of Brazil, is used by most of fishfarmers on 24 hours' immersion bath. The present study submitted 64 jundias (Rhamdia quelen), infested by Lernaea cyprinacea under four treatments $(0,0 \mathrm{mg} / \mathrm{L} ; 0,01 \mathrm{mg} / \mathrm{L} ; 0,1 \mathrm{mgmg} / \mathrm{L}$ and $1 \mathrm{mg} / \mathrm{L})$ at immersion bath during 24 hours. At final of experimental period, we carried through the collect and evaluation of fish sperm. No differences were found over evaluated parameters: volume, aspect (appearance and color), motility duration and concentration of sperm. The product showed inefficient as 24 hours' immersion bath against adult parasites and copepodites.
\end{abstract}

Key words: Sperm, motility, concentration of sperm, bath, Rhamdia, Laernaea cyprinacea, diflubenzuron.

1 Graduação em Medicina Veterinária. Mestrado em Zootecnia. Pesquisador da SAA-RSl.

2 Professora Doutora do Departamento de Zootecnia, Faculdade de Agronomia, UFRGS. E-mail: silsouza@ufrgs.br

3 Professora doutora do Departamento de Patologia Clínica Veterinária, Faculdade de Veterinária, UFRGS.

Autor para correspondência 


\section{Introdução}

As substâncias indiscriminadamente usadas no tratamento de doenças de peixes são um risco para o ambiente e conseqüentemente para o homem. Segundo Mabilia et al. (2003), em pisciculturas no estado do Rio Grande do Sul, o percentual de uso de produtos no tratamento de lerneose é muito elevado, ficando assim distribuído: 19,04\% avermectinas, 9,52\% organofosforados e 33,33\% para o diflubenzuron. Este último produto é capaz de reduzir abruptamente o desenvolvimento e a reprodução de zooplancton (CUNNINGHAM, 1986). Há também evidências de toxicidade, imunotoxicidade e carcinogenicidade em ratos e camundongos em relação a um de seus metabólitos, o 4-cloroanilina (CHHABRA et al., 1990,1991).

Os peixes são freqüentemente apontados como bio-indicadores da presença de substâncias químicas na água, seja através de estudos de mortalidade, de hematologia, de alterações histo-patológicas, de sêmen, entre outras metodologias. Nos últimos anos, a observação dos impactos de inseticidas e outros poluentes sobre a produção espermática de várias espécies tem sido objeto de pesquisas. Moore e Waring (2001) sugeriram que baixo nível de cipermetrina (piretróide sintético) na água causou efeito negativo nas funções reprodutivas do salmão do Atlântico. Os autores verificaram que a exposição de machos maduros por cinco (5) dias a uma concentração menor que $0,004 \mathrm{mu} \mathrm{g/} \mathrm{super-1} \mathrm{cipermetrina,} \mathrm{reduziu}$ significativamente a resposta olfatória aos feromônios. Isso foi confirmado pelo não aumento do $17 \alpha 20 \beta$ pregnen-3-one no plasma e conseqüentemente no incremento do sêmen extrusável. Lahnsteiner, Mansour e Berger (2004) avaliaram a motilidade de sêmen em teleósteos expostos a metais pesados, nitrito, 2,4-diclorofenol e ciclohexano, sendo que o sêmen do "catfish" africano foi o menos sensível entre todas as espécies estudadas.

A espécie em estudo, um "catfish" brasileiro, o jundiá (Rhamdia quelen), é altamente suscetível a Lernaea cyprinacea e o diflubenzuron é o pesticida mais usado na terapêutica deste ectoparasito.
O primeiro trabalho sobre sêmen no gênero Rhamdia spp no Brasil data de 1985, desenvolvido por Silveira, Kavamoto e Narahara (1985) usando animais com $21,9 \mathrm{~cm}$ e $89,73 \mathrm{~g}$ de comprimento e peso médio, respectivamente. Borges et al. (2005), trabalhando com a composição seminal e características do sêmen de jundiá, observaram maior qualidade de sêmen durante a primavera.

O objetivo deste trabalho foi verificar os efeitos do banho com DFB, durante um período 24 horas, sobre as características do sêmen jundiá.

\section{Material e Métodos}

O Experimento foi realizado no mês de agosto, no Setor de Aqüicultura da Faculdade de Agronomia da Universidade Federal do Rio Grande do Sul, situado na cidade de Porto Alegre, $30,16^{\circ} \mathrm{S}$ e $51,16^{\circ} \mathrm{W}$.

Os animais estudados foram jundiás (Rhamdia quelen) oriundos de uma estação de piscicultura do noroeste do estado do Rio Grande do Sul. O período pré-experimental foi de 20 dias, sendo 100 machos mantidos em tanque de alvenaria de $10.000 \mathrm{~L}$, com renovação de água diária na taxa de $25 \%$ e arraçoamento com ração peletizada da Marca Supra Peixe Juvenil ${ }^{\circledR}$ na ordem de $2 \%$ da biomassa em duas refeições diárias.

Para a exposição ao banho de DFB, as unidades experimentais (UE) eram mantidas em caixas de água de 1000 litros. Cada unidade experimental recebia aeração constante. A qualidade da água foi monitorada no início e final do banho de imersão. Os parâmetros avaliados foram: OD (oxigênio dissolvido), pH, alcalinidade, dureza, amônia total, amônia não ionizada e nitrito.

Para o diagnóstico parasitário dos copepoditos infectantes realizou-se raspado cutâneo e secção dos arcos branquiais de $5 \%$ dos exemplares, para visualização sob microscopia óptica de luz, em aumento de 10x. Os parasitas adultos foram visualizados macroscopicamente.

Foram utilizados 64 peixes ( $R$.quelen) com peso médio de $190 \pm 26$ gramas, sendo divididos em quatro 
tratamentos com quatro repetições. Cada repetição era formada por quatro indivíduos, totalizando 16 animais para cada tratamento. Os tratamentos se constituíram de banhos de imersão por um período de 24 horas com DFB na dosagem de 0,01 mg. ${ }^{-1}$, 0,1 mg. $\mathrm{L}^{-1}, 1 \mathrm{mg} . \mathrm{L}^{-1}$, além de um grupo controle, onde não foi administrado o DFB. A menor dose está de acordo com Post (1987), para tratamento da lerneose. Os banhos foram de 24 horas, numa única aplicação, como ocorre no protocolo adotado por piscicultores na região Sul do país.

Ao final do período experimental, foram realizadas a coleta e a avaliação do sêmen dos peixes. As características avaliadas foram: volume, aspecto (aparência e cor), duração da motilidade e concentração espermática.

O volume de sêmen foi mensurado de acordo com (KAVAMOTO; SILVEIRA, 1986). Uma seringa plástica de $1 \mathrm{~mL}$ foi colocada em contacto com a papila genital do macho. A aspiração de sêmen foi realizada no momento da verificação da ausência de urina.

A coloração e o aspecto do sêmen foram avaliados visualmente, observando-se a cor e a densidade aparente (cremosa, leitosa ou aquosa) das amostras.

A duração da motilidade foi avaliada através do tempo cronometrado entre a ativação espermática (inicio da movimentação) até a ausência total da movimentação, conforme Defrapoint e Sorensen (1993). A ativação da motilidade foi realizada diluindo-se $0,5 \mu \mathrm{L}$ de sêmen em $200 \mu \mathrm{L}$ de água sobre uma lâmina, sendo imediatamente examinada ao microscópico com a objetiva de 40x, conforme Mabília et al., (2003), em experimentos anteriores realizados no Setor de Aqüicultura da Universidade Federal do Rio Grande do Sul.

A concentração espermática foi realizada pela contagem de células na câmara hematimétrica de Neubauer e expressa em número de espermatozóides $/ \mathrm{mm}^{3}$. O sêmen foi diluído a 1:5000 (MABÍLIA et al., 2003) em solução formol-salina com citrato de sódio a 3\% (PINHEIRO; SOUZA; BARCELLOS, 2003).

\section{Resultados e Discussão}

Os valores médios e o desvio padrão das características do sêmen avaliadas estão expressos na Tabela 1. O volume médio do sêmen foi de $0,37 \pm 0,18 \mathrm{~mL}$, no grupo controle, de $0,36 \pm 0,37$ $\mathrm{mL}$, no T1, de $0,40 \pm 0,25 \mathrm{~mL}$ no $\mathrm{T} 2$ e de $0,36 \pm 0,23$ mLno T3. Como os dados não atendiam à condição de normalidade, pela presença de quatro valores "outliers", foi realizado o teste não paramétrico Kruskal-Wallis que não evidenciou diferença significativa entre os tratamentos $(\mathrm{H}=0,4782$ e $\mathrm{p}=0,9236$ ). Valores próximos aos "outliers" foram encontrados por Silveira, Kavamoto e Narahara (1985) 1,15 $\pm 0,44 \mathrm{~mL}$ ( amplitude de 2,0-0,5 mL) ; Ferreira et al. (2001) 0,41 $\pm 0,37$ (amplitude de 1,10$0,11 \mathrm{~mL}$ ) e Borges et al. (2005) durante um ciclo reprodutivo observaram um volume de $0,95 \pm 0,08$ na primavera e de $0,24 \pm 0,03$ no inverno.

Durante as 24 horas do experimento os parâmetros de qualidade da água foram os seguintes: temperatura, $22-27^{\circ} \mathrm{C}$; oxigênio dissolvido $6-8 \mathrm{mg} /$ L. A amônia total permaneceu em $0,25 \mathrm{mg} / \mathrm{L}$ e o $\mathrm{pH}$ 7,0; níveis considerados adequados para a espécie..

Com relação ao aspecto do sêmen, 47 ejaculados apresentaram-se leitosos, um cremoso, e um opalescente. Quanto à cor, 48 ejaculados mostraramse brancos e um esbranquiçado. Os valores médios da concentração espermática estão bem próximos daqueles encontrados por Silveira, Kavamoto e Narahara (1985) e Borges et al. (2005).

O tempo de duração da motilidade não apresentou diferença entre os tratamentos, variando entre 44,76 $\pm 16,88$ e 55,08 $\pm 8,08$ s. Estes valores são semelhantes aos observados na primavera por Borges et al. (2005). A ausência de variação entre os grupos está de acordo com o observado por Lahnsteiner, Mansour e Berger, (2004), que referiram que a motilidade espermática não pode ser considerada um bom parâmetro como bio-indicador da presença de poluentes. Os autores utilizaram água com diferentes poluentes como ativador da motilidade espermática e não verificaram alterações 
significativas nesta característica espermática. Consideraram, ainda, que existe grande variação na morfologiaemetabolismo espermático entre os peixes, o que determina diferentes graus de sensibilidade aos poluentes. Em condições naturais, Scholz (2000) considera que somente o 2,4-diclorofenol e o zinco podem ocorrer em concentrações capazes de afetar a motilidade espermática de peixes. Outros poluentes como cádmio, níquel, mercúrio, chumbo e cobre seriam letais aos peixes antes de poder causar efeitos na motilidade.

Estudos recentes referem que o acúmulo de poluentes poderia afetar negativamente o processo da espermatogênese e interferir nos parâmetros reprodutivos de peixes.(JOBLING et al., 1996, 2002; FLAMMARION et al., 2000). No presente estudo, pode-se considerar que o banho de 24 horas não produziu efeitos nas características de sêmen estudadas, tanto pelo fato da ativação da motilidade ter sido realizada com água destilada, como também em razão do curto tempo de ação do produto, sugerindo ser insuficiente para determinar efeitos nas características de sêmen. Quanto às concentrações, a dose considerada terapêutica $(0,01$ $\mathrm{mg} / \mathrm{L})$ e as subseqüentes, 100 e 1000 vezes superior àquela, também não mostraram diferença no tempo de motilidade espermática.

As mesmas concentrações não apresentaram diferenças significativas nos parâmetros hematológicos dos peixes (MABILIA; SOUZA, 2006). Com relação ao controle da Lernaea cyprinacea, o produto mostrou-se ineficaz em banhos de 24 horas, para os parasitos adultos e copepoditos.

Novos trabalhos, para avaliar um período de exposição mais prolongado dos peixes ao diflubenzuron devem ser conduzidos, para verificar a possibilidade de efeitos deletérios na espermatogênese desta espécie.

Tabela 1. Volume do sêmen (média, desvio padrão e amplitude), concentração espermática (C.E.) (média e desvio padrão), tempo de motilidade (T.M., média e desvio padrão) de jundiás (Rhamdia quelen), submetidos a banho com diflubenzuron, pelo período de 24 horas.

\begin{tabular}{lrrrrr}
\hline \multirow{2}{*}{ Tratamento } & \multicolumn{3}{c}{ Volume $(\mathrm{mL})$} & \multirow{2}{*}{ C.E. $\left(x 10^{6} / \mathrm{mm}^{3}\right)$} & \multirow{2}{*}{ T.M. (seg.) } \\
\cline { 2 - 3 } Controle & $0,37 \pm 0,18$ & $0,12 \quad 0,61$ & $52,14 \pm 14,54$ & $55,08 \pm 8,08$ \\
$0,01 \mathrm{mg} / \mathrm{L}$ & $0,36 \pm 0,37$ & $0,10 \quad 1,20$ & $50,92 \pm 11,59$ & $53,38 \pm 10,70$ \\
$0,1 \mathrm{mg} / \mathrm{L}$ & $0,40 \pm 0,25$ & $0,10 \quad 1,00$ & $52,00 \pm 13,95$ & $49,73 \pm 10,86$ \\
$1,0 \mathrm{mg} / \mathrm{L}$ & $0,36 \pm 0,23$ & $0,10 \quad 1,00$ & $52,60 \pm 20,33$ & $44,76 \pm 16,88$ \\
\hline
\end{tabular}

\section{Referências}

BORGES, A.; SIQUEIRA, D. S.; JURINITZ, D. F.; ZANINI, F. A.; GRILLO, M. L.; OBERST, E. R.; WASSERMANN, G. F. Biochemical composition of seminal plasma and annual variations in semen characteristics of jundiá Rhamdia quelen (Quoy and Gaimard, Pimelodidae). Fish Physiology and Biochemistry, Amsterdam, v. 31, n. 1, p. 45-53, 2005.

CHHABRA, R. S.; HUFF, J. E.; HASEMAN, J. K.; ELWELL, M. R.; PETERS, A. C. Carcinogenicity of p-chloroaniline in rats and mice. Food and Chemical Toxicology, Oxford, v. 29, n. 2, p. 119-24, 1991.
CHHABRA, R. S.; THOMPSOM, M.; ELWELL, M. R.; GERKEN, D. K. Toxicity of p-chloroaniline in rats and mice. Food and Chemical Toxicology, Oxford, v. 28, n. 10, p. 717-722, 1990.

CUNNINGHAM, P. A. A review of toxicity testing and degradation studies used to predict the effects of diflubenzuron (Dimilin $\left.{ }^{\circledR}\right)$ on estuarine crustaceans. Environmental Pollution: Ecological and Biological. (Series A), London, v. 40, n. 1, p.63-86, 1986.

DEFRAPOINT, M.; SORENSEN, P.W. Exposure to the pheromone 17alfa.20beta-dihydroxy-4-pregen-3one enchances the behavioural spawing success, sperm production and sperm motility of male goldfish. Animal Behaviour, London, v. 46, p. 245-256, 1993. 
FERREIRA, A. A.; NUÑER, A. P. O.; LUZ, R. K.; TATAJE, D. A. R.; ESQUIVEL, J. R.; RESTREPO, J. B. Avaliação qualiquantitativa do sêmen do jundiá, Rhamdia quelen. Boletim do Instituto de Pesca, São Paulo, v. 27, n. 1, p. 57-60, 2001.

FLAMMARION, P.; BRION, F.; BABUT, M.; GARRIE, J.; MIGEON, B.; NOURY, P.; THYBAUD, E.; TYLER, C. R.; PALAZZI, X. Induction of fish vitellogenin and alterations in testicular structure Preliminary results of estrogenic effects in chub; (Leuciscus cephalus). Ecotoxicology, London, v. 9, n. 1-2, p. 127-135, 2000.

JOBLING, S.; COEY, S.; WHITMORE, J. G.; KIME, D. E.; VANLOOK, K. J. W.; MCALLISTER, B. G.; BERESFORD, N.; HENSHAW, A. C.; BRIGHTY, G.; TYLER, C. R.; SUMPTER, J. P. Wild intersex roach (Rutilus rutilus) have reduced fertility. Biology of Reproduction, Champaign, v. 67, n. 2, p. 515-524, 2002.

JOBLING, W.; SHEAHAN, D. A.; OSBORNE, J. A.; MATTHIESSEN, P.; SUMPTER, J. P. Inhibition of testicular growth in rainbow trout; (Oncorhynchus mykiss) exposed to estrogenic alkyphenolic chemicals. Environmental Toxicology and Chemistry, New York, v. 15, p. 194-202, 1996.

KAVAMOTO, E. T.; SILVEIRA, W. F. Características físicas, químicas e microscópicas do sêmen do bagre, Rhamdia hilarii (Valenciennes, 1840) em condições de campo. Boletim do Instituto de Pesca, São Paulo, v. 13, n. 1, p. 95-100, 1986.

LAHNSTEINER, F.; MANSOUR, N.; BERGER, B. The effect of inorganic and organic pollutants on sperm motility of some freshwater teleosts. Journal of Fish Biology, London, v.65, n. 5, p. 1283-1297, 2004.
MABILIA, R. G.; SOUZA, S. M. G. Efeito do tratamento com diflubenzuron na hematologia de Jundiás (Rhamdia quelen) infestados pelo copepoda Lernaea cyprinacea em banhos de imersão de 24 horas. Acta Scientiarum: Biological Sciences, Maringá, v. 28, n. 2, p. 159-163, 2006.

MABILIA, R. G.; SOUZA, S. M. G.; BARCELLOS, L. J. G.; NETO, J. B. Human corionic gonadotrophin's (HCG) influence on physical characteristics in the spermogram of Jundiá (Rhamdia quelen). In: WORLD CONFERENCE ON ANIMAL PRODUCTION, 9., 2003, Porto Alegre, RS. Resumos... Porto Alegre: ALPA, 2003. p. 183.

MOORE, A.; WARING, C. P. The effects of a synthetic pyrethroid pesticide on some aspects of reproduction in Atlantic salmon (Salmo salar L.). Aquatic-Toxicology, Amsterdam, v. 52, n. 1, p.1-12, 2001.

PINHEIRO, M. F. M.; SOUZA, S. M. G.; BARCELLOS, L. Exposure to $17 \alpha, 20 \beta$-dihydroxy-4-pregnen-3one changes seminal characteristics in Nile tilapia, Oreochromis niloticus. Aquaculture Research, Stirling, v. 34, n. 12, p. 1047-1052, 2003.

POST, G. Textbook of fish health. Canada: TFH Publications, 1987.

SCHOLZ, B. Environmental handbook documentation on monitoring and evaluating and development (BMZ), environmental impacts. Berlin: Federal Ministry for Economic Cooperation, 2000. v.3.

SILVEIRA, W.; KAVAMOTO, E. T.; NARAHARA, M. Y. Avaliação da qualidade e crio-preservação em forma de "pellets" do sêmen do bagre, Rhamdia hilarii (Valenciennes, 1840), Boletim Instituto de Pesca, São Paulo, v. 12, n. 4, p. 7-11, dez. 1985. 
